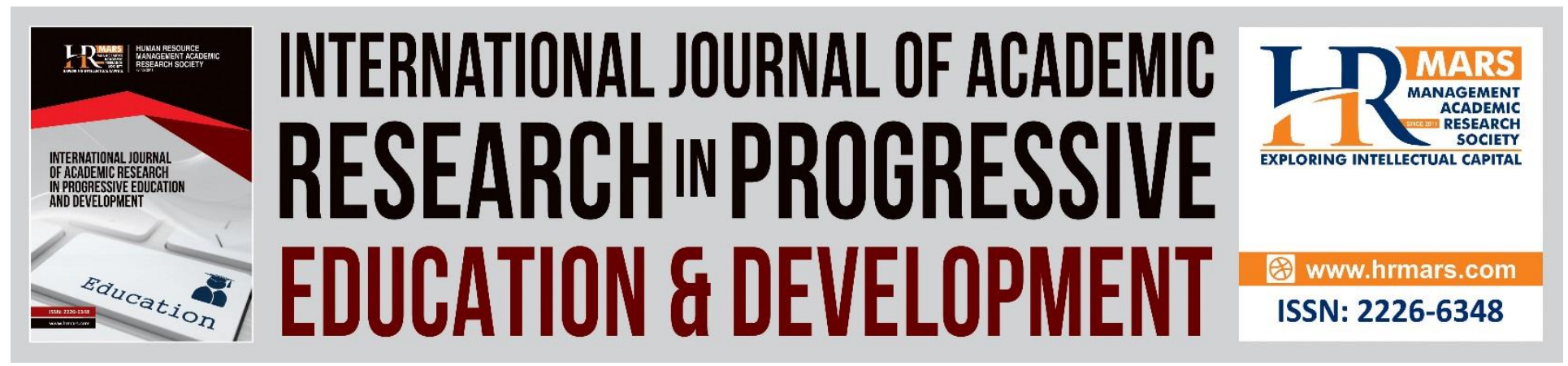

\title{
Comparative Study of Factors Affecting the Performances of Soccer Referees: The Case of Oromia Soccer Higher League
}

\section{Berhanu Tesema Guta}

To Link this Article: http://dx.doi.org/10.6007/IJARPED/v9-i4/7996

DOI:10.6007/IJARPED/v9-i4/7996

Received: 28 October 2020, Revised: 24 November 2020, Accepted: 18 December 2020

Published Online: 30 December 2020

In-Text Citation: (Guta, 2020)

To Cite this Article: Guta, B. T. (2020). Comparative Study of Factors Affecting the Performances of Soccer Referees: The Case of Oromia Soccer Higher League. International Journal of Academic Research in Progressive Education and Development, 9(4), 35-52.

Copyright: (C) 2020 The Author(s)

Published by Human Resource Management Academic Research Society (www.hrmars.com)

This article is published under the Creative Commons Attribution (CC BY 4.0) license. Anyone may reproduce, distribute, translate and create derivative works of this article (for both commercial and non-commercial purposes), subject to full attribution to the original publication and authors. The full terms of this license may be seen at: http://creativecommons.org/licences/by/4.0/legalcode

\section{Vol. 9 (4) 2020, Pg. 35 - 52}

Full Terms \& Conditions of access and use can be found at http://hrmars.com/index.php/pages/detail/publication-ethics 


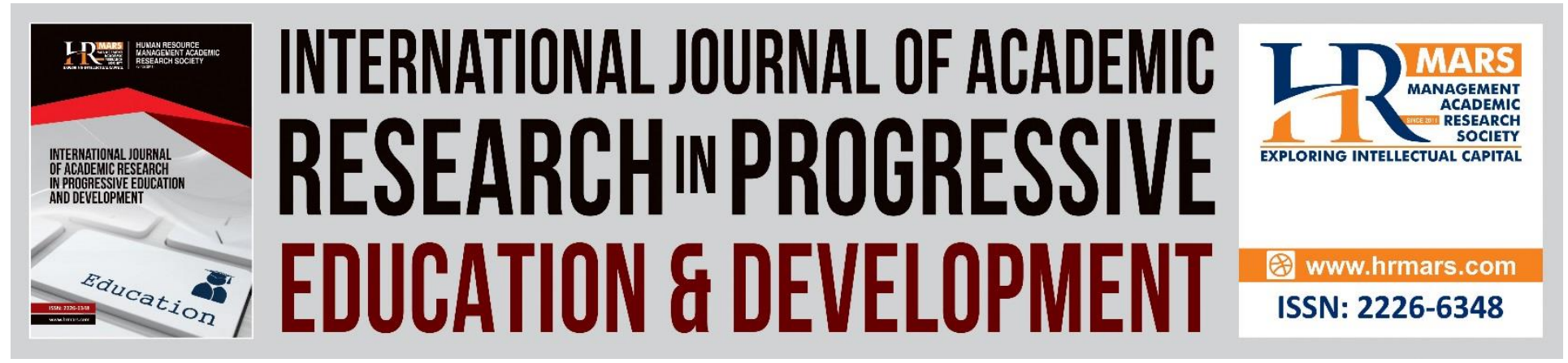

\title{
Comparative Study of Factors Affecting the Performances of Soccer Referees: The Case of Oromia Soccer Higher League
}

\author{
Berhanu Tesema Guta (Ass.Prof.) \\ Department of Physical Education, Nekemte College of Teacher Education, Nekemte, Oromia \\ Email: btesema35@gmail.com
}

\begin{abstract}
The primary purpose of this study was to compare factors affecting the performances of soccer referees in Oromia regional state soccer higher league. The research groups were composed of 68 referees group and 72 coaching staff carefully chosen using a comprehensive sampling technique. The data were collected using five options Likert scale analyzed and compared with statistical procedures in which the calculated mean, standard deviation, and t-test involved. In the process to obtain sample t-test output via (SPSS Vs.20), the p-value labeled as "Sig (2 tailed)" decision making, mental and physical demands, the skill of game management and psychological aspects of referees ( $P$-value $\leq 047>0.000$ ), indicated statistically significant differences, whereas, corruption and referees bias ( $P$-value is 0.091 ), implying that there was no statistically significant difference at the level of 0.05 . Conclusion from the investigation indicate that soccer referees have been implementing unfair decision making and pitiable quality of skill in-game management, exhibit bias in favor of home team, low level of psychological, mental and physical aspects observed while the soccer game was in progress. Therefore, the researcher recommended that an appropriate selection criterion set to recruit future referees to promote their technical,and performance related affairs of decision making and club managers, coaches, and players to be more careful with their testimonials during the game.
\end{abstract}

Keywords: Factors, Performance, Referee, Soccer, Decision Making

\section{Introduction}

Studies made so far indicate that refereeing in sport originated during the first Olympic Games in the ancient Greeks. The roles of referees at the time were used to selecting athletes, managing the training of the participants, directing the game, refereeing soccer competitions, and deciding on the required sanctions related to the rule of the game (Bagnall et al., 2013). At present, many football referees' work in the majority of competitive games surveyed reflects 
empirical evidence in connection with the diversity of referee tasks and their complexity (Dosseville, \& Laborde, 2011).

The sports referee is an individual who is on the field of play to manage the application of soccer rules. As a result of this, arbitration is a task done in the area through actions, decisions, and methods. This concern functions services as a bridge between the spectator and footballer and opponent teams in which referees ensure the evaluation of play within the predetermined possibility (Cei, 1994).

The role of a soccer referee is significantly crucial in a soccer match. Accordingly, Collina(2004) identifies five essential functions of soccer referees 1) referees know, apply and give comments on rules of the game, 2) physically fit and have the physiological capacity, 3) practices every functional distinctiveness in the field, 4) brave, decisive and fair, 5) should have a continuous awareness for deep revision, complete evaluation of the game, rapid decisions should equally carry out in every competition, communicate players, coaches, and managers in a friendly manner cited in (Karakus, 2011).

To fit the standards, referees must have exceptional skills (McMahon et al, 2006). Appropriate physical preparation is a factor permitting referees to absorb and process much information (Mallo et al., 2007). Less than twenty years ago, the decisions taken by referees' suitability for officiating the game at a given level mainly made about different aspects of visual abilities and the assessment of physical conditioning (Mallo et al, 2007).

In recent years, soccer's economic growth has increased referees' physical, physiological, and psychological demands in implementing soccer rules (Castagna et al, 2007). In a similar vein, soccer management skills, especially decision-making, are scientific like other sectors and require education and experience. Referees in the soccer field are accountable for directing referees' teams and their management skills in decision-making that affect the behavioral actions of all players, coaches, and practitioners of competitions and clubs as a whole (Hampton, 2006).

In other ways, the impacts of corruption and referee bias are not unique in soccer but can also observe in other sports such as basketball or baseball. (Sutter and Martin, 2004) classify that soccer referees were influencing to add extra time while the home team did not try to win the opponent team. (Garicano et al., 2005) referee bias depends on the number of spectators watching the match, and (Dawson et al., 2007) team playing away is more likely to face sanctions from the referees than the home team. (Dohmen, 2005; Scoppa, 2008) emphasize the effect of the type of stadium (with or without running track) and crowds proximity to the field on home team bias cited in (Dohmen \& Sauermann, 2015).

Of course, the existence of referee bias extending or shortening injury-time does not necessarily imply dishonesty in a soccer game. Such bias might be a consequence of social pressure exerted by the crowd, which either consciously or unconsciously affects a soccer referee's decisions. In supporting the idea specified above, (Garicano et al., 2005) reveal that the bias increases on attendance by approximately one standard deviation and the ratio of presence to stadium capacity in Spain (Dohmen, 2005; Lucey \& Power, 2009; Scoppa, 2008) reports the crowd proximity measured by whether or not there is a running track in the field tends to increase the degree of unfairness.

It's known that referees most often make mistakes at the end of each half of a match or during the last minutes. First of all, this is physical fatigue, which accumulated during the game 
and lowers alertness, and causes referee decision-making more slowly in controversial situations (Oh et al., 2011)

There is evidence to suggest that soccer played in the half of 20 centuries in the study area; there was no professional league established in the country until now-nevertheless, in the last fifteen years. According to the experience, observation, and professional disquiet of the researcher of this study soccer referees were fully charged red and yellow card unfairly, irresponsible for making the game flow, influenced, corrupting the rules of the game, and serving as partial judges of conduct. In the view of such information, the researcher of this study attempted to compare the possible factors that affect football referees' performances in Oromia regional state soccer higher League.

\section{Statements of the Problem}

Soccer has become a social incidence that brings people together, attracting the attention of millions all over the world. The enormous financial dimension of soccer makes the effective conduct of the matches a critical issue that shifts ways beyond being a simple event influencing soccer players, referees, club managers, and the spectators. In most soccer games, the phenomenon of social pressure on soccer referees' decision-making has always played a critical role. It affects the outcome of important events related to the performances of soccer referees.

Accordingly, (Cengiz, 2004) refereeing is one of the professions that require the ability to make many decisions within a fraction of time, and immediate decisions completed at frequent intervals,. Therefore, attention and concentration are vital and must be at an extreme level. The decisions made rapidly and in quick succession are made under high pressure. The effects of referees' physiological and psychological states have a significant influence at every point in the game taken into consideration at present. Soccer referees should make the right decisions by keeping under control of psychological elements such as anxiety, fear, and stress.

Equally, refereeing is a physical action with psychological and mental aspects (Cei, 1994) Referees must conduct the matches objectively by making healthy decisions following the rules of the game. Although the number of studies in the field of sports has increased in the last two decades, there are limited studies relating to sports refereeing (Hoar et al, 2006).

Most of the issues related to the professional activities of referees in football are not thoroughly studied. The past studies indicate multiple factors might influence sports referees' decisions, i.e., pressure from spectators and athletes' reputation grounded in the social impact theory framework, factors influencing soccer referee's intentions to quit the game, factors relating to the decision-making performance of soccer referees, and evaluation of the factors that affect performances of active football referees (Vyzirgiannakis et al., 2018; Cellena et al, 2014; Elsworthy et al., 2014; Seydi, 2011) respectively.

Set the present study was to fulfill the research gap that contributes to the achievement of official rules in determining the appropriate approach may the referees encounter concerning decision making, mental and physical demands of referees, the skill of game management, corruption, and referees bias and referees psychological aspects, can significantly influence the performances of soccer referees of Oromia regional state soccer higher League. To this effect, the following research questions anticipated exploring factors affecting soccer referees' accounts while the game of soccer was in progress. 
1) What are the significant factors affecting the performances of soccer referees?

2) Is there a significant difference between the coaching staff and referees group on each factor predicted in affecting soccer referees' performances?

3) Is there no significant difference between the coaching staff and referees group on each factor affecting soccer referees' performances?

\section{Review of Related Literature \\ Mental and Physical Demands of Referees}

There is a close relationship between psychological skills and the physical performance of soccer referees. So, the success or failure of referee depends upon their physical abilities (the preparation for the specific demands of a given sport, the technique mobility, and visual skills) and mental (confidence, concentration, emotional control are satisfying (Weinberg, 2010).

Consequently, the condition taken to make a special referee seems to combine physical and mental skills. The best sort of mixture will see more clearly when looking at the essential qualities of a right referee call for a specific technical knowledge; there is an art in becoming an outstanding soccer referee. Besides, the referee's skill during the game depends mainly on their personal qualities (Weinberg, 2010).

Accordingly, (Weston et al., 2012) state the excellent level of physical fitness to ensure referees can keep up the game at all times and obtain optimal positions when making critical decisions. Physical training programs informed by the science of match analysis would appear logical. In contrast, material considerations will always be secondary to the ability to fulfill a technical role in the play, and inadequate physical preparation could limit soccer referees' technical functioning during the match (Mendez-Villanueva \& Buchheit, 2013).

(Fruchart \& Carton, 2012) suggests that physiological changes in advancing age result in the declines of aerobic and anaerobic performance, with speed and power that most affected physiological demands of football referees. On this premise, (Johnson, 2016) points out the failure of performance in the general cooper test fitness, but accurately.

Further, this study conducted to investigate the relationship between soccer referees' physical and cognitive demands. Consequently, (Verheijen et al, 2002) examine the correct and incorrect decision-making of elite soccer referees. So, the referees typically moved more slowly when they made the right decisions; therefore, they recommended that they make correct decisions when walking rather than running.

The gradual reduction of high intensity running and backward running amongst referees in the second half differences in estimated energy expended between the first and second halves (Mallo et al, 2007) cited in (Mascarenhas et al., 2009).

\section{Decision-Making and Soccer Referees}

The recent empirical evidence suggested the decisions of soccer referees motivated by the laws of the game accurate (Plessner and Betsch, 2002) and game management to ensure the flow of the game to be unbiased (Mascarenhas et al., 2002) as cited by (Bar-Eli et al, 2011).

Of course, (Federation International de Football Association., 2013) rules give referees a vital role and responsibility in a soccer competition played by two teams. The central referee has 
full authority to apply the game laws in connection to the match he/she assigned and facts, including whether or not a goal scored and the result of the game completed.

Several researchers surveyed the underlying mechanisms that led to incorrect decision making of soccer referees. The central referee decisions are strongly influenced by crowd noise, whereas flash-lag optical error explains all flag and a large portion of non-flag mistakes made by assistant referees (Helsen et al., 2007) and (McMahon et al, 2006). The nearer the soccer referees to the action resulted from the less the decision-making error. (Tomlinson, 2014) reported that the central and assistant referees run several kilometers per game to be as close as possible to the action.

Numerous factors are interrupting the decision-making processes of the soccer referee. For instance, effective choices should take into account the laws of the game relevant to any past events and with the situational context of the game at the time (Mascarenhas et al, 2002) and the positioning of the referee and interaction with assistant referees (Thomas \& Gregson, 2006).

Furthermore, research has begun to consider factors that might affect the quality of referees' decisions. For instance, there is some compelling evidence that referee bias contributes to home advantage in football. Exercise can also induce fatigue that negatively impacts referees' decision-making (Boyko et al, 2007), and (Mascarenhas et al, 2006) recommend muscular fatigue accumulates during exercise causes heavier stress upon central neural control that may parallel by considering the effect of response biases (home-field advantage), fatigue, the movements of speed increased mental load and less time spent to take decision making (Verheijen et al, 2002). Also, increasing attention directed towards assistant referees impaired performance when their speed of movement increases to run or sprint (Oudejans et al, 2005).

The additional study investigates the conscious use of a destabilization strategy during a soccer match will allow amateur referees to demonstrate their capacity to control a game while being marked by observers based on the practical measurement method aimed at identifying the influence of different factors on a destabilization decision (Anderson, 2008).

The first factor was physical tiredness that influences a soccer referee (Mascarenhas et al., 2009). The intensity of the match and fatigue can affect the cognitive functioning quality of decision making the central referee (Reilly, 1997). Fatigue does not seem to harm offside decision-making by assistant referees (Catteeuw et al, 2010). The second factor was considered referee communication with players. (Mellick et al., 2005) demonstrate the importance of using verbal and non-verbal techniques to enhance player acceptance of decisions and influence players' perceptions concerning the correctness of decisions that go against them (Simmons, 2008).The third factor considered the referee's level of aggression, Verbal aggression directed against referees as experienced as unpleasant (Friman et al., 2004). Continually, amateur referees suffer from verbal attacks from players, coaches, and spectators (Folkesson et al., 2002).The fourth factor was considered the evaluation of soccer referees in applying and controlling the game rules to achieve excellent performance by the observer (Thomas Reilly \& Gregson, 2006). (Nuytens et al, 2010) indicate the best referees will upgrade and the worst one will downgrade at the end of the sports season makes this mark very important.

The last factor considered linked up with emotions, and more particularly how calm the referee during the match influences his/her decision-making. (Simmons, 2008) advanced that referees must appear smooth to prevent and manage player aggression following refereeing 
decision making. In another study, (Krettenauer et al., 2011) show the influence of emotions in adolescents' moral decision-making in the soccer game.

\section{Corruption and Referee Bias in Football}

The academic literature has extensively studied the role and impartiality of referees in the game. Several studies investigated the extent to which the external forces persuade the referee to make incorrect decisions. The fact is that playing at home and social effects such as the composition of the crowd, type of the stadium, and the proximity crowd' to the playground have an impact on referees' decision making even if referees do not get any advantage for their biased behaviors. The literature has mainly focused on the analysis of home team bias, i.e., the extent to which referees tend to bias in favor of home teams. Several studies revealed home team bias and argue the pressure from home fans tends to influence referees' decision making (Boyko et al., 2007).

The type of advantage taken in the field has been measuring the added extra time, penalties kick, yellow and red card sanctions, free-kicks, and offside awards. Consequently, empirical papers investigating the home team bias's existence seem to be straightforward and consistent across countries. Accordingly, (Garicano et al, 2005) in Spanish Laliga, Division Garicano et al., (2005); (Dohmen, 2005) in German Bundesliga, (Dawson et al, 2007) in English Premier League expose biased referees decisions can contribute to the phenomenon of home advantage in a soccer competition.

\section{Psychological Aspects of Soccer Referees}

Refereeing is one of the professions that require the ability to make many decisions within a fraction of time, and immediate decisions must have completed at frequent intervals. Attention and concentration are vital and must be at an extreme level, the decisions made rapidly and in quick succession formed under high pressure. Accordingly, the effects of referees' physiological and psychological states have a significant influence at every point in the game taken into consideration at present. Supplementary, soccer referees shoud make the right decisions by keeping under control of psychological elements such as anxiety, fear, and stress (Cengiz, 2004).

Psychological readiness of a soccer referee is an action taken after reading the players' minds and behaviors before, during, and after conforming to the game's laws. The following factors, however, to a large extent affect the referee's psychology, i.e.,(a) the knowledge of the rules of the game and its appropriate application(b) the size of the spectators; overwhelmingly large (c) the composition of the spectators, referees committee members, and other referees (d) the distance of the crowd from the referee (e) the attitude of the crowd ( $f$ ) influence of the home crowd (g) the experience of the referee; years of refereeing, age about the players, exposure and (h) the health condition of the referee (Agbovi, 2007) quoted in (SayfollahPour, 2013).

\section{Materials and Methods}

\section{Study Method and Desired Population}

The present study aimed to review the literature regarding the factors affecting referees ' performance quality in sporting fields, especially soccer. The study was comparative and descriptive. This study's sample populations were soccer referees, team managers, head and 
assistant coaches, and team captains selected using comprehensive random sampling techniques. Therefore, the research groups contained 181 target populations ( 87 senior, junior referees, commissioners, and 94 team managers, coaches, and team captains of 18 Oromia soccer higher leagues) who actively participated in football season schedules by Oromia regional state Football Federation Association in 2018/2019.

\section{Instruments of Data Collection}

A close and open-ended questionnaire planned for data collection, a semi-structured interview utilized as a second data collection instrument, and the observation was used as third sources of qualitative data to integrate the significant problems in connection with the performances of soccer referees in the Oromia Regional state into the final analysis for triangulation purposes.

\section{Data Analysis}

The data were analyzed and compared using Statistical Package for the Social Sciences (SPSS; version 20.01). Arithmetic means, standard deviation, and independent sample " $\mathrm{t}$ " test was used to compare the procedures of data. As a result, " $t$ " values anticipated being valid either less than or greater than 0.05 considering statistically significants.

\section{Data Analysis and Interpretation}

This chapter deals with the procedure of data analysis and interpretation that obtained through mean-value and independent-sample t-test related to comparing factors affecting the performances of soccer referees. To this effect, the questionnaires distributed to $181(100 \%)$ of desire populations. Amongst 87(48.06\%) were seniors, junior referees and Commissioners and 94(51.94\%) of them were team managers, coaches and team captains. However, the total return rates of the questionnaires were $140(77.77 \%)$ through which $68(37.77 \%)$ of the copies collected from referees' group and $72(40 \%)$ of the return rate gathered from coaching staff respectively. Nevertheless, the researcher of this study enforced to missed the complete returned rates of the questionnaires from $41(23.33 \%)$ of respondents

\section{Demographic characteristics of Respondent}

Out of the total participant of the study, $43.57 \%$ of them estimated between the age of $25-31,25 \%$ of the participant grouped between the middle age of $32-38,12.86 \%$ of respondents categorized adult of $18-24$ years, and $12.14 \%$ of them rated into $39-45$ years old and $6 \%$ of them greater than 45 years respectively. Regarding their gender, 138 (98.58\%) of the respondents were male to the contrary of this view, $2(1.42 \%)$ of them were female as depicted in table 1. Concerning educational background of the participants of the study, 55(39.29\%) high school, 33(23.57\%) were diploma holders, 25(17.86\%) graduates of a degree program, 22(15.71\%) certificate, fewer or $5(3.57 \%)$ of the respondents of this study have their masters in various area of specialization. 
INTERNATIONAL JOURNAL OF ACADEMIC RESEARCH IN PROGRESSIVE EDUCATION AND DEVELOPMENT

Vol. 9, No. 4, 2020, E-ISSN: $2226-6348$ @ 2020 HRMARS

Table 1 Age, sex, and Educational background of respondents

\begin{tabular}{|c|c|c|c|c|}
\hline Variables & Category & $n$ & $\%$ & Total \\
\hline & $18-24$ & 18 & 12.8 & \multirow{9}{*}{$\begin{array}{l}140 \\
(100 \%)\end{array}$} \\
\hline & & & 6 & \\
\hline \multirow[t]{7}{*}{ Age } & $25-31$ & 61 & 43.5 & \\
\hline & & & 7 & \\
\hline & $32-38$ & 35 & 25.0 & \\
\hline & & & 0 & \\
\hline & $39-45$ & 17 & 12.1 & \\
\hline & & & 4 & \\
\hline & $>45$ & 9 & 6.43 & \\
\hline \multirow[t]{3}{*}{ Sex } & $M$ & 138 & 98.5 & \multirow{3}{*}{$\begin{array}{l}140 \\
(100 \%)\end{array}$} \\
\hline & & & 8 & \\
\hline & $\mathrm{F}$ & 2 & 1.42 & \\
\hline \multirow{9}{*}{$\begin{array}{l}\text { Educational } \\
\text { background }\end{array}$} & High & 55 & 39.2 & \multirow{9}{*}{$\begin{array}{l}140 \\
(100 \%\end{array}$} \\
\hline & School & & 9 & \\
\hline & Certificate & 22 & 15.7 & \\
\hline & & & 1 & \\
\hline & Diploma & 33 & 23.5 & \\
\hline & & & 7 & \\
\hline & Degree & 25 & 17.8 & \\
\hline & & & 6 & \\
\hline & Masters & 5 & 3.57 & \\
\hline
\end{tabular}

Table 2: Job, Active Arbitration Years and Arbitration Degree of respondents

\begin{tabular}{lllll}
\hline Variables & Sub-category & $\mathbf{N}$ & $\mathbf{\%}$ & Total \\
\hline Job & Officials & 0 & 0 & \\
& Self-Employer & 8 & 5.57 & 140 \\
& Gove. & 132 & 94.43 & $(100 \%$ \\
& Employee & & & \\
Active arbitration Years & $3-7$ & 18 & 12.86 & \\
& $8-12$ & 45 & 32.14 & 140 \\
& $12-16$ & 60 & 42.85 & $(100 \%$ \\
Arbitration & $>16$ & 17 & 12.14 & \\
& FIFA referees & 0 & 0 & 68 \\
& Senior referees & 49 & 34.99 & $(48.57 \%)$ \\
& Assistant & 15 & 10.72 & \\
& referees & & & \\
Marital Status & Commissioners & 4 & 2.86 & 140 \\
& Married & 106 & 75.72 & $(100 \%$ \\
& Single & 34 & 24.29 & \\
\hline
\end{tabular}


In association with respondent jobs categories, 132(94.43\%) of them were governmental workers, on the other hand, $8(5.57 \%)$ of them were self- employers as shown in table 2 . The participants of this study were asked their active arbitration years (period). Hence, $18(12.86 \%)$ estimated from 3 to 7 years, $45(32.14 \%$ ) experienced from $8-12$ years, 60 (42.85\%) of them were energetic arbitration of 12-16 years whereas, $17(12.14 \%)$ of them were involved in referee functioning for greater than 16 years. According to the information gathered concerning the arbitration degree of the referee, therefore, 49 (34.99\%) of them were the senior referee. Nevertheless, 15 (10.72\%) of them holding the position of assistant referees, and $4(2.86 \%)$ of them were commissioners as depicted in table 2. Hence, anyone can conclude that majority of soccer referees assigned to judge Oromia soccer higher league competition were seniors with 12-16 active arbitration years. In respects with respondents marital status, $106(75.72 \%)$ married and $34(24.29 \%)$ of them were single.

Table 3. Responses Comparatives on Factors Affecting the Performances of Soccer Referees

\begin{tabular}{|c|c|c|c|c|}
\hline \multirow[b]{2}{*}{ Factors } & \multicolumn{2}{|l|}{ Mean } & \multicolumn{2}{|c|}{ St.Deviation } \\
\hline & Referee & coach & Referee & Coach \\
\hline Decision making & 2.53 & 3.55 & 1.581 & .854 \\
\hline $\begin{array}{l}\text { Mental and physical } \\
\text { demands }\end{array}$ & 2.97 & 3.00 & 1.368 & .986 \\
\hline Corruption and referee bias & 3.66 & 3.183 & 1.29 & 0.959 \\
\hline Game management & 2.98 & 2.569 & 1.351 & 0.744 \\
\hline Psychological aspects & 2.028 & 3.790 & 1.11 & 0.647 \\
\hline
\end{tabular}

\section{Result and Discussion}

As shown in Table 3, the coaching staff average scores in responding to decision making, mental and physical demands, and psychological aspects of soccer referees estimated $3.55,3.00$, and 3.79. In contrast, the average scours $(2.53,2.97$, and 2.03), implies that coaching staff exposes the realities related to referee's decision making, mental and physical demands, and psychological factors mainly affecting the performances of referees than referees group respectively.

In the same table, the average scores of the soccer referees in response to referee's game management and referees bias in soccer game anticipated 3.66 and 2.98 while, the mean scores of the coaching staff optional 3.18 and 2. 57. The participants of the referees' group confirmed that the significant performance to the contrary in which coaching staff reveals the low performances of referees in applying the law the game. 
INTERNATIONAL JOURNAL OF ACADEMIC RESEARCH IN PROGRESSIVE EDUCATION AND DEVELOPMENT

Vol. 9, No. 4, 2020, E-ISSN: $2226-6348$ @ 2020 HRMARS

Table 4. Referees and Coaching Staff Preferences of Factors Affects R.P in Rank Order

\begin{tabular}{|c|c|c|c|c|c|c|}
\hline \multirow[t]{3}{*}{ Factors } & \multicolumn{2}{|c|}{ Referees Group } & \multicolumn{4}{|c|}{ Coaching Staff } \\
\hline & \multirow[b]{2}{*}{ Mean } & \multirow[b]{2}{*}{ Std. D } & \multirow[b]{2}{*}{ Rank } & \multicolumn{2}{|c|}{ Mea } & \multirow[b]{2}{*}{ Rank } \\
\hline & & & & $\mathrm{n}$ & Std. D & \\
\hline Decision Making & 2.53 & 1.58 & 4 & 3.55 & .854 & 2 \\
\hline $\begin{array}{l}\text { Mental and physical } \\
\text { demands }\end{array}$ & 2.97 & 1.37 & 3 & 3.00 & .986 & 4 \\
\hline $\begin{array}{l}\text { Corruption and referee } \\
\text { bias }\end{array}$ & 3.66 & 1.29 & 1 & 3.18 & 0.959 & 3 \\
\hline Game management & 2.99 & 1.35 & 2 & 2.57 & 0.74 & 5 \\
\hline Psychological aspects & 2.03 & 1.11 & 5 & 3.79 & 0.647 & 1 \\
\hline
\end{tabular}

In table 4 above, corruption and referee bias in soccer have the highest significance of 3.66 for the referees' group. Whereas, coaching staff ranked this factor in second place with a mean score of 3.18. With regards to game management referees group was ordered at second place with the average mean of 2.99; on the other hand, it ranked by coaching staff at fifth with the average value of 2.57 .

A mental and physical demand of referees was the third preferred by referees group with an average value of 2.97 while coaching staff optional at third position with a mean value of 3.00. The referees' group choose the decision making of referees at fourth place with an average mean-value of 2.53 , but this factor took second place to be employed by coaching staff with an average mean-value of 3.55. Though, referees favored elements mainly affect referee's psychological aspects with 2.03 average mean scores in the fifth place. Still, coaching staff employs this factors group in the first place with a mean score of 3.79 in the area depicted in table 4.

Table 5. Results of the Independent Samples T-test on Decision-making of Referees

\begin{tabular}{clllll}
\hline $\begin{array}{c}\text { Levene's Test for } \\
\begin{array}{c}\text { Equality of } \\
\text { Variances }\end{array}\end{array}$ & \multicolumn{4}{c}{$\begin{array}{l}\text { t-test for Equality of } \\
\text { Means }\end{array}$} \\
\hline$F$ & Sig. & $t$ & $d f$ & $P$ & $M D$ \\
\hline 118.16 & .135 & 3.596 & 138 & .000 & $\begin{array}{l}1.00 \\
4\end{array}$ \\
& & & & & 4 \\
\hline
\end{tabular}

* $t$ " values (3.596) determines, P-values (0.000) at significant level of 0.05

As shown in table 5 , the calculated independent simple" $t$ " test was to determine the mean and standard deviation of participants of the study whether or not referees were performing decision-making while the soccer game was in progress. The intended independent sample "ttest estimated (3.596), and the statistical significance of $p$-values is 0.000 . Hence, the " $t$ ' value is higher than $p$-values at a significant level of 0.05 with 138 degrees of freedom. There was statistically significant differences between the two groups. The main task of soccer referees during the match is to safeguard the application of the laws of the game, considered a decisionmaking process that essential for correct decision-making. Hence, the interview respondents and the researcher observation results revealed that the crowd noise, team reputation, home 
advantages, lack of confidence, and concentration were equally limited the substantial number of referee's decisions making.

The performance of the soccer referee's decision-making present in this study was precisely in line with previous studies by (Goumas, 2014) which states that the central referee's decisions are strongly influenced by crowd noise. Balmer et al. (2007) crowd sound, experience and anxiety affecting mainly, and Lane, Nevill, Ahamad and Balmer (2006) identified four categories of limitations influencing soccer referee decision-making: ideal decision-making (accuracy-error, regulations, and professionalism), individual factors (opinion, concentration, and control), experience factors (experience, personality, personal life) and situational factors (crowd interaction, environmental factors, player reaction, crowd factors) cited in (SayfollahPour, 2013). Referee decision-making can affect the course of a game and sports actors' behavior. Indeed, some decisions can inflame a match, get supporters or coach exited, or led players to behave in such a way that their misconduct cannot make up. Otherwise, referees can also calm down various social tensions and diminish excessive behavior (Friman et al., 2004)

Table 6. Results of Independent Samples T-test on Mental and Physical Demands of Referees

\begin{tabular}{|c|c|c|c|c|c|}
\hline \multicolumn{2}{|c|}{$\begin{array}{l}\text { Levene's Test for } \\
\text { Equality of } \\
\text { Variances }\end{array}$} & \multicolumn{4}{|c|}{ t-test for Equality of Means } \\
\hline $\mathrm{F}$ & Sig & $\mathrm{T}$ & $\mathrm{df}$ & $p$ & M.D. \\
\hline 46.334 & 0.207 & 2.04 & 138 & 0.000 & 0.326 \\
\hline
\end{tabular}

As indicated in table 6, Levene's test for equality of variances of mental and physical demands of refereeing shows that the significant value intended to 0.207 was greater than 0.05 . Therefore, they assumed that the variances were equal, and the mean difference was 0.326 . Additionally, the $t$-value similar to $2.04(P=0.000)$ in which " $t$ " values were more magnificent than "P" at a significant level of .05. Thus, there was statistically significant difference between the subjects. In support of the data calculated using the " $t$ " value, the participants of the interviews and researcher observation cheek-list confirmed that inadequate physical fitness could limit the technical functioning of soccer referees during the match.

In supporting the information gathered through questionnaires, there are researches which prove mutual unity of physical and intellectual activity verified in the study that human's mental and physical condition intensely and mutually affect each other very important in sport (Xibaev, 2009). The intellectual level is a significant factor in achieving excellent results in the gameseveral types of research link mental capacity to succeed in the competition. Notably, the link between intellect and education level is an emphasis; that is, athletes having higher I.Q not only accomplish more in the game but also have a higher education level (Vazne et al, 2008). 
INTERNATIONAL JOURNAL OF ACADEMIC RESEARCH IN PROGRESSIVE EDUCATION AND

DEVELOPMENT

Vol. 9, No. 4, 2020, E-ISSN: $2226-6348$ @ 2020 HRMARS

Table 7. Results of Independent Sample T-test on Corruption and Referees Bias

\begin{tabular}{lccccc}
\hline $\begin{array}{l}\text { Levene's Test for } \\
\text { Equality of } \\
\text { Variances }\end{array}$ & & \multicolumn{4}{c}{ t-test for Equality of Means } \\
\hline $\mathrm{F}$ & $\mathrm{Sig}$ & $\mathrm{t}$ & $\mathrm{df}$ & $\mathrm{p}$ & $\mathrm{M} . \mathrm{D}$. \\
\hline 46.334 & .207 & 2.172 & 138 & .091 & 0.326 \\
\hline values (2.172) & determines, $P(0.091)$ & at significant level of 0.05
\end{tabular}

Results displayed in table 7 above show that Levene's test for equality of variances, the significance Value was 0.207 greater than .05 . Therefore, they assumed that the difference was equal. And the t-value was $2.172(p=.091)$ in which $t$-value was more significant than $P$-value at a considerable level of .05 with 138 degrees of freedom. Consequently, anyone can conclude that there was no statistical significant difference between the two groups of the study.

According to interviewee responses and continuous observation cheek-list, carryout by researcher suggestion on corruption and referees' bias found that during 2018/2019 Oromia soccer higher League season home teams were legitimately awarded $65 \%$ of all penalty kicks. In contrast, visiting teams awarded only $35 \%$ of all penalties kick.

The remuneration to the crowd is much higher so that social pressure might be concentrate and top (Dawson \& Dobson, 2010), (T. J. Dohmen, 2008) finds that a more significant fraction of awarded penalty kicks either wrongly awarded or disputable when the home team is one goal behind (Coleman, 1988) investigate soccer referees bias regarding penalty kicks, goals award, free kicks, red and yellow cards confirmation of home biased referees on penalty kick decisions making is more inaccurate.

Table 8. The Results of Independent Sample T-test for Participants on Game Managements of Soccer Referees

\begin{tabular}{|c|c|c|c|c|c|}
\hline \multicolumn{2}{|c|}{$\begin{array}{l}\text { Levene's Test for } \\
\text { Equality of Variances }\end{array}$} & \multicolumn{4}{|c|}{ t-test for Equality of Means } \\
\hline $\mathrm{F}$ & Sig & $\mathrm{t}$ & $d f$ & $p$ & M.D. \\
\hline 36.46 & .000 & 1.968 & 138 & .000 & 0.416 \\
\hline
\end{tabular}

The variances were assumed to be Levene's test for equality, and the t-value for items 2830 were1.968 $(p=0.000)$. Thus, $p$-values less than $t$-value at a significant level of .05 with 138 degrees of freedom. As a result, it determined a statistically significant difference between the two groups in responding to referees performing game management skills. The interview and observation data suggested a strong desire to referees games management inappropriately and inaccurately implementing the rules and regulations soccer with full of error and bias.

Useful game management qualities contained in this study as a critical factor affecting the performance of football referees. However, (Kurtic, 2006) confirm that soccer referees know the skill and talents of players on the ball and quickly calculate the probability of success of players. Table 9.The results of Independent Sample T-test of Participants on Psychological Aspects of Soccer Referees 


\begin{tabular}{|c|c|c|c|c|c|}
\hline \multicolumn{2}{|c|}{$\begin{array}{l}\text { Levenes Test for } \\
\text { Equality of } \\
\text { Variances }\end{array}$} & \multicolumn{4}{|c|}{ t-test for Equality of Means } \\
\hline$F$ & Sig. & $t$ & $d f$ & $p$ & M.D. \\
\hline 45.756 & .122 & 4.90 & 138 & .047 & 45.758 \\
\hline
\end{tabular}

As indicated in table 9, Levene's test for equality of variances shows that the significant value was 0.122 , which was more significant than .05 . Therefore, it assumed that the differences were equal. Additionally, the t-value was $4.90(p=0.047)$, which was less than 0.05 at significant levels .05. Thus, it can conclude that there was significant difference between the two groups on factors that mainly affects the psychological aspects of soccer referees

The finding of this study also related to the influences on the referee himself to behave in a particular manner in conformity with the laws of the game during the match, the extent to which factors significant effect the 'referee's psychology (Agbovi, 2007) cited in (SayfollahPour, 2013) specified in the review of related literature. The information gathered using the interview and observation checklist of the researcher was confirmed the same result in line with Agbovi, 2007 investigations.

\section{Conclusion}

Based on this study's finding, the following conclusion focused on comparing the significant factors that obstructed the implementation of soccer referee's performances during soccer matches in Oromia soccer higher League in progress. The preliminary study compared factors affecting soccer referees' performance between the respondent groups of referees and coaching staff.

Hypothesia1: The intended t-test was to determine the mean and standard deviation between this study participants. The average mean value of coaching staff confirmed that corruption and referees bias, the skill of game management, mental and physical demands, decision making and psychological aspects rated in raking order respectively; on the other hand, the referee's groups identified the level of factors, i.e., psychological aspect, decision making, corruption, and referee bias, mental and physical demands, and referees skill of game management correspondingly. This implies that the predicted hypotheses anticipated the outcomes of comparison expected the relationship between the dependent and independent variables, which are inversely affecting the performance of soccer referees in the study area(see Table 3 and 4).

Hypothesis 2: The result obtained using independent sample t-test concluded that $p$-values were less than t-value at a significant level of .05 with 138 degrees of freedom revealing the presences of statistically significant difference between the two groups of participants considering decision making, mental and physical demands, Psychological aspects and the skill of referees' game management (see table 5,6,8 and 9).

Hypothesis 3: The study's findings focused on corruption and referee bias of soccer referees exposed that $p$-value was more significant than alpha at a significance level of 0.05 amongst the 
two groups of participants. This concludes that there were no statistically significant differences between the two groups (see Table 7 ).

In supporting the finding calculated and analyzed through quantitative, the results of the interview and continuous observations checklist of researcher revealed that soccer referees' implemented unfair decisions making, reflects inadequate physical fitness, the existence of corruption and referee bias, imbalanced quality of skill in-game management, and the low level of psychological aspects were significantly affecting the performances of soccer referees.

\section{Recommendations}

Based on the findings, the following recommendations suggested by the writer of this paper, assuming that they could be the solution for the problems encountered in soccer referees' performances in Oromia regional state soccer higher League.

1. Referees should have cognition skills to anticipate the actions of the persons involved in the game to know which effects to observe and make them fast and apply the excellent decision.

2. We can understand that soccer game referees do not only involve knowing rules very well and the practical application. Therefore, there should be various qualities in mental, physical, physiological, and psychological performances.

3. Oromia Football Federation Association should provide a strong foundation for developing an educational program designed to teach referees to cope with situational stressors such as crowd noise and anxieties to minimize referee's reasons for giving each decision on a decision by decision basis.

4. The concept of love, respect, and fair play, which are continuously emphasized by FIFA and C.A.F., should be infused into the individuals' beginners from young ages without ignoring the moral values of the society.

5. Official referees and assistant referees should communicate, providing official soccer referees' signals to minimize the risks of aggressive behavior and violence from footballers, spectators, and negative statements of club managers and coaches.

6. Sports researchers in Oromia should conduct further studies to remove political and economic factors which influence the development of soccer competitions

\section{Acknowledgments}

Heavenly Father, I praise you with eternal gratitude, for I am pleased in your eyes, and you have been my strength and foundation during the progression of this study. I also acknowledge Mr. Wakshum Regasa Kitila (Wollege Global Football club manager) for his genuine contribution in distributing and collecting the questionnaires from respondents of the study with unlimited attention. I am very much thankful to Fiseha Berhanu Tesema (Ph.D.) for his critical edition and constructive comments has excellent credit to me in my life. Fainally, my Special thanks goes to Zinaw Berhanu Tesema (MSc) for his decisive contribution in software application for data analysis and APA format. 
INTERNATIONAL JOURNAL OF ACADEMIC RESEARCH IN PROGRESSIVE EDUCATION AND

DEVELOPMENT

Vol. 9, No. 4, 2020, E-ISSN: $2226-6348$ @ 2020 HRMARS

\section{References}

Anderson, N. H. (2008). Unified social cognition. New York. Psychology Press.

Bagnall, R. S., Brodersen, K., Champion, C. B., Erskine, A., \& Huebner, S. R. (2013). The encyclopedia of ancient history (Vol. 1). Wiley-Blackwell.

Bar-Eli, M., Plessner, H., \& Raab, M. (2011). Judgment, decision-making and success in sport. John Wiley \& Sons.

Boyko, R. H., Boyko, A. R., \& Boyko, M. G. (2007). Referee bias contributes to home advantage in English Premiership football. Journal of Sports Sciences, 25(11), 1185-1194.

Castagna, C., Abt, G., \& D'Ottavio, S. (2007). Physiological aspects of soccer refereeing performance and training. Sports Medicine, 37(7), 625-646.

Catteeuw, P., Gilis, B., Wagemans, J., \& Helsen, W. (2010). Offside decision making of assistant referees in the English Premier League: Impact of physical and perceptual-cognitive factors on match performance. Journal of Sports Sciences, 28(5), 471-481.

Cei A. (1994). Arbitration psychology. Translated by: Kin A. J. Football Scientific Technolgy. 21-23.

Dell, C. M. G., \& Rhind, D. A. (2014). Factors influencing soccer referee's intentions to quit the game. Journal of Soccer and Society, 17(1).

Cengiz, R. P. A. (2004). Perspectives on the events fair play of the referees. Sports Philosophy and Social Sciences Symposium of Celal Bayar University.

Coleman, J. S. (1988). Free Riders and Zealots: The Role of Social Networks, Sociological Theory.

Dawson, P., \& Dobson, S. (2010). The influence of social pressure and nationality on individual decisions: Evidence from the behaviour of referees. Journal of Economic Psychology, 31(2), 181-191.

Dawson, P., Dobson, S., Goddard, J., \& Wilson, J. (2007). Are football referees really biased and inconsistent?: evidence on the incidence of disciplinary sanction in the English Premier League. Journal of the Royal Statistical Society: Series A (Statistics in Society), 170(1), 231250.

Dohmen, T. J. (2005). Social pressure influences decisions of individuals: Evidence from the behavior of football referees.

Dohmen, T. J. (2008). The influence of social forces: Evidence from the behavior of football referees. Economic Inquiry, 46(3), 411-424.

Dohmen, T., \& Sauermann, J. (2015). Referee Bias. Institute of Labor Economics (IZA).

Dosseville, F., \& Laborde, S. (2011). Athletes' expectations concerning officiating competence. European , . Journal of Sport Science, 448--450.

Elsworthy, N., Burke, D., \& Dascombe, J. Ben. (2014). Factors relating to the decision-making performance of Australian football officials. International Journal of Performance Analysis in Sport, 14(2), 401-410.

Federation International de Football Association. (2013). Laws of the game. Paper presented at 127th Annual General Meeting of the International Football Association Board (IFAB); Edinburgh, Scotland.

Folkesson, P., Nyberg, C., Archer, T., \& Norlander, T. (2002). Soccer referees' experience of threat and aggression: Effects of age, experience, and life orientation on outcome of coping strategy. Aggressive Behavior: Official Journal of the International Society for Research on Aggression, 28(4), 317-327. 
INTERNATIONAL JOURNAL OF ACADEMIC RESEARCH IN PROGRESSIVE EDUCATION AND

DEVELOPMENT

Vol. 9, No. 4, 2020, E-ISSN: $2226-6348$ @ 2020 HRMARS

Friman, M., Nyberg, C., \& Norlander, T. (2004). Threats and aggression directed at soccer referees: An empirical phenomenological psychological study. The Qualitative Report, 9(4), 652-672.

Fruchart, E., \& Carton, A. (2012). How Do Amateur Soccer Referees Destabilize a Match?. Psicólogica: International Journal of Methodology and Experimental Psychology, 33(3), 435449.

Johnson, J. (2016). Cognitive modeling of decision making in sports. Psychology of Sport and Exercise.

Garicano, L., Palacios-Huerta, I., \& Prendergast, C. (2005). Favoritism under social pressure. Review of Economics and Statistics, 87(2), 208-216.

Goumas, C. (2014). Home advantage in Australian soccer. Journal of Science and Medicine in Sport, 17(1), 119-123.

Hampton, M. (2006). The bigger picture, Capital referee London, FA.

Helsen, W., Gilis, B., \& Weston, M. (2007). Helsen, Gilis, and Weston do not err in questioning the optical error hypothesis as the only major account for explaining offside decision-making errors. Journal of Sports Sciences, 25(9), 991-994.

Hoar, S. D., Kowalski, K. C., Gaudreau, P., \& Crocker, P. R. E. (2006). A review of coping in sport. Literature Reviews in Sport Psychology, 47-90.

Krettenauer, T., Jia, F., \& Mosleh, M. (2011). The role of emotion expectancies in adolescents' moral decision making. Journal of Experimental Child Psychology, 108(2), 358-370.

Kurtic, N. (2006). Psycho-social factors are leading to violence among football supporters. Unpublished Master's Thesis.Sakarya University Institute of Social Sciences, Sakarya.

Lucey, B. M., \& Power, D. (2009). Do soccer referees display home bias? Available at SSRN 552223.

Mallo, J., Navarro, E., García-Aranda, J.-M., Gilis, B., \& Helsen, W. (2007). Activity profile of topclass association football referees in relation to performance in selected physical tests. Journal of Sports Sciences, 25(7), 805-813.

Mascarenhas, D., O Hare, D., \& Plessner, H. (2006). The psychological and performance demands of association football refereeing. International Journal of Sport Psychology, 37(2/3), 99.

Mascarenhas, D. R. D., Button, C., O’Hare, D., \& Dicks, M. (2009). Physical performance and decision making in association football referees: A naturalistic study. The Open Sports Sciences Journal, 2(1).

McMahon, C., Helsen, W., Starkes, J., \& Weston, M. (2006). Decision-making skills and deliberate practice in elite association football referees. Journal of Sports Sciences.

Mellick, M. C., Fleming, S., Bull, P., \& Laugharne, E. J. (2005). Identifying best practice for referee decision communication in association and rugby union football. Football Studies, 8(1), 4257.

Mendez-Villanueva, A., \& Buchheit, M. (2013). Football-specific fitness testing: adding value or confirming the evidence? Journal of Sports Sciences, 31(13), 1503-1508.

Nuytens, W., Hidry-Neys, H., Pen in, N., \& Sallow, L. (2010). Closer to actions. Closer to gestures: Research report ARCIR. Unpublished manuscript, University of Artois, laboratory SHERPAS, Lievin, France.

Oh, I.-S., Wang, G., \& Mount, M. K. (2011). Validity of observer ratings of the five-factor model of 
personality traits: a meta-analysis. Journal of Applied Psychology, 96(4), 762.

Oudejans, R. R. D., Bakker, F. C., Verheijen, R., Gerrits, J. C., Steinbrückner, M., \& Beek, P. J. (2005). How position and motion of expert assistant referees in soccer relate to the quality or their offside judgements during actual match play. International Journal of Sport Psychology.

Reilly, T. (1997). Energetics of high-intensity exercise (soccer) with particular reference to fatigue. Journal of Sports Sciences, 15(3), 257-263.

Reilly, Thomas, \& Gregson, W. (2006). Special populations: The referee and assistant referee. Journal of Sports Sciences, 24(07), 795-801.

SayfollahPour, P. (2013). A Consideration of the Factors Influencing Soccer Referees' Judgment? An Overview. International Journal of Academic Research in Business and Social Sciences, 3(5), 678.

Scoppa, V. (2008). Are subjective evaluations biased by social factors or connections? An econometric analysis of soccer referee decisions. Empirical Economics, 35(1), 123-140.

Simmons, P. (2008). Justice, culture, and football referee communication. Final report of Joao Have Lange Research Scholarship study to FIFA / CIES Scientific Committee, Switzerland.

Sutter, M. M. G. K. (2004). Favouritism of agents'. The case of referees' home bias. Journal of Economic Psychology, 25, . 461--469.

Tomlinson, A. (2014). FIFA (Fédération internationale de football association): the men, the myths and the money. Routledge.

Vazne, Z., Rudzitis, A., Larkin's, V. (2008). June basketbolistu psiholoiisk as sagatavot '`bas faktoru structurer. ATEE Spring University. Teacher of the 21st Century: Quality Education for quality teaching. $R^{-}$Iga: $L U$, Pp.126--134.

Verheijen, R., Oudejans, R. R. D., Beek, P. J. B. F. C. (2002). Factors affecting the decision-making of soccer referees. In: Spinks W, Reilly T, Murphy A, Eds. Fourth World Congress of Science and Football. Sydney, Routledge, 28.

Vyzirgiannakis, D., Siokos, K., Kagkarakis, P., Pereira, V., \& Papanikolaou, Z. (2018). Factors affecting the performance of Greek soccer referees of super league and football league.

Weinberg. (2010). The psychological qualities of a good referee: Posted by SCRRS Website Committee on December 16th, 2010(Adapted from WEINBERG: Psychology of refereeing).

Weston, M., Castagna, C., Impellizzeri, F. M., Bizzini, M., Williams, A. M., \& Gregson, W. (2012). Science and medicine applied to soccer refereeing. Sports Medicine, 42(7), 615-631.

Xibaev A. V. (2009). Razvitie professionalno znaqimyh psihofiziologiqeskih kaqestv futbolnyh arbitrov, Retrieved 